\title{
Evaluating the risk of bacterial infections associated with the most handled Iraqi notes in Kalar
}

\author{
Mohammed Hassan Fatah \\ Medical Lab. Technology Department \\ Kalar Technical Institute \\ Sulaimani Polytechnic University \\ Kalar, Iraq \\ Mohammed.fatah@spu.edu.iq
}

\author{
Ahmed Mohammed Tofiq \\ Biology Department \\ College of Education \\ Garmian University \\ Kalar, Iraq \\ Ahmed.mohammed@garmian.edu.krd
}

\author{
Hassan Mohammad Tawfeeq \\ Nursing Department \\ Kalar Technical Institute \\ Sulaimani Polytechnic University \\ Kalar, Iraq \\ Hassan.tawfeeq@spu.edu.iq
}

\begin{abstract}
Everyday new sources of microbial and especially bacterial infections are reported, which are not taken into account, the fact that these sources have been implicated in the outbreaks of these infections. The goals of the current research focused on the exploration of the scope of microbial pollution of the widely traded paper currency notes of the Iraqi currencies (250, 1000 and 5000 Iraqi Dinars) in Kalar city. 300 banknotes (100 samples for each of the denominations under investigation) in circulation were gathered from different categories of Kalar population and one fresh sample for each of the three currencies (control negative). Each bill was rinsed in $5 \mathrm{ml} \mathrm{D.W}$ then cultured on Nutrient agar, Mannitol Salt agar and MacConkey agar, respectively, then incubated at $37{ }^{\circ} \mathrm{C}$ for up to 48 hours. Results revealed the rate of microbial contamination, specifically bacterial ones as $94 \%, 68 \%$, and $60 \%$, respectively on the denominations of 250, 1000, and 5000 of Iraqi Dinars. In a descending order, and with regard to the prevalence rate, bacterial species contaminated 250, 1000 and 5000 Iraqi denominations respectively were as follows: $55.31 \%$, $32.35 \%$ and $36.66 \%$ for Bacillus sp.; $14.89 \%$, 38.23\% and $20 \%$ for coagulase negative Staphylococcus; $8.51 \%, 8.82 \%$ and $20 \%$ for E. coli; $2.12 \%, 11.76$ and $20 \%$ for pseudomonas sp.; $2.12 \%$ for each of Klebsiella sp., and Salmonella sp.; $10.63 \%$ and $4.25 \%$ for Enterobacter sp. and Staphylococcus aureus, respectively, and only on 250 denomination; $2.94 \%$ and $5.88 \%$ for each of Corynebacterium sp. and Serratia sp. only on 1000 currency note; lastly, 3.33\% for Proteus sp. on 5000 IQD only. These outcomes suggest that bacterial contamination of Iraqi Dinars, specifically the 250 denomination is risky and could be regarded as the real source of infectious diseases with the most dangerous pathogenic bacteria.
\end{abstract}

Keywords: Iraqi paper currencies, Bacterial contamination, risky pathogenic bacteria, Kalar city

\section{INTRODUCTION}

Since the settlement of humans on the planet, they used currency for the exchange of all the forms of commodities. This means that money has been implemented in various aspects of human's daily life in addition to saving. Numerous microorganisms, including pathogenic can be transmitted by contaminated money when they are passing to other people [1]. One of the sources of the sudden onset of bacterial infections is paper currency with immense surface area, since pathogens can exploit it as a breeding ground [2]. High level of microbial contamination of paper currencies have been reported in another studies carried out in disparate countries of the world [3].

During counting, currency notes can get contaminated with diverse microbes from respiratory and digestive tract [1]. Numerous human's daily activities are the sources of notes contamination. For example, it could be through coughing and sneezing droplets, using saliva when counting the notes, soil, dust, water, dirty wounds, handlers skin and hands micro-flora, contacting with preceding polluted hands or extra stuffs and emplacement on grubby work surfaces. Moreover, few manners of managing money including, maintaining denominations within brassiere, pockets, socks, beneath the mattresses and pressing in the hands, consistently initiate microorganisms to the currency notes [4]. However, it should be known that paper note is not providing favorable environment for the growth and maintenance of microorganisms, excluding those that are able to withstand external harsh environmental parameters and spores $[5,6]$. The disparity in the social and health levels of society is also one of the important factors that will increase the chance of the contamination of money by different types of bacteria, especially the pathogenic ones. For example, money with those who work in processing of fresh, wetting foods from agricultural fields till it reach consumers are more susceptible to contamination because of the moisture of the handlers traded compared to the circulation of money with the hands of other classes. In India, paper currency is usually contaminated with bacteria of medically important, this in turn have a great impact on the transposal of diverse infectious diseases. Citizens and related governmental institutions are fully aware of the dispersal of pathogenic microorganisms via food, water, air and have already taken the necessary measures to overcome this problem. However, it seems like that they are not concerned about some of the habits like putting saliva on some fingers while enumerating paper currencies which are extensively swapped between hands, depicts a general intermediate for the microbial 
transmission in the environment and amongst humans as well, which increase the probability of acquiring infection [1].

Socioeconomic, climatic and various microbiological elements obviously known to be worldwide interlinked are shown to be closely interconnected with the advent of infectious diseases. Population growth, urbanizations, unhygienic, poverty and even bioterrorism are the driven forces for the incidence of such diseases. It has been clarified by a considerable review that contaminated fomites and currency notes play a critical role in the dissemination of microbial infections with antibiotic resistance [7]. Staphylococcus, E. coli and Pseudomonas were among the most prospective pathogens that have been isolated from currency notes [8]. ExtendedSpectrum Beta Lactamases (ESBL) producing Escherichia coli and Klebsiella sp. that are evolved as antimicrobial resistance species, are widely known as multi-drug resistant microorganisms that are shown to contaminate banknotes and coins that contribute in their transmission to the community [9]. This indicates more complicated medical cases, and turns out to face difficulties in the management.

The outcome of cross-sectional studies carried out for the microbial screening of polluted paper currencies may differ, owing to the procedure applied, climate, and a kind of currency or local microbial community of the normal flora, and principally, the most prevalent bacteria were Gram positive ones [10]. As long as the problem of the spread of pathogenic bacteria through currency and coins is universal, therefore, it is really essential to do such screening in Kalar city, which is one of the big cities in Kurdistan region. Moreover, and to the best of our knowledge, there isn't any published data in this concern. There is no doubt that in places where credit cards are less used by people for their daily needs, they will be more vulnerable to infections through contaminated currency and coins, and that is the condition where we are in. Therefore, this study has been conducted to make the first ever data about bacterial profile of Iraqi paper currency gathered from different communities of the fore-mentioned city.

\section{METHODS AND MATERIALS}

\subsection{Study Area and design}

The Iraqi currency notes were gathered from Kalar, the biggest city which belongs to Sulaimani province and as one of the ancient colonial cities in Kurdistan regionIraq. In this city all sort of Iraqi paper currency denominations were randomly gathered from everyday use from March 2018 to August 2018 and processing of the collected samples were carried out at Medical Laboratory Technology Department, Kalar Technical Institute. The protocol of the current study was approved by the local Institutional Scientific and Ethics Committee.

\subsection{Sample Collection}

A total of 303 samples of Iraqi denominations (100 pieces of each denomination) were gathered for the required analyses. 300 specimens of the Iraqi notes (250, 1000 and 5000) were collected in a randomised manner by exchanging paper currencies from different people
(Drivers, teachers, traders, bus conductors, store keepers and other individuals) while 3 samples were gathered from Central Bank of Iraq (CBI), Kalar branch which utilised as the control. For the purpose of paper currency collection, the individuals were asked to drop currency notes directly into a well prepared sterile disposable plastic bag and labelled properly; paper currencies were not picked up by the investigator using bare hands at any time and any step. Packets were sealed and promptly transferred to the Microbiology laboratory for microbiological analysis.

\subsection{Media Preparation and Microbial Analyses}

Culture media utilized for isolation and primary identification of microorganisms included nutrient agar, MacConkey agar and mannitol salt agar. Various media that used in isolation and identification were prepared following manufacturer's instructions.

\subsection{Microbiological Analyses of the Samples}

Each of the samples was gathered and soaked in $5 \mathrm{ml}$ aliquots of sterile distilled water, then the tubes vigorously shaken for up to 2 minutes to dislodge microbial cells into the intended suspension at ambient temperature. Denominations removed and the resulting suspension of distilled water solution served as the test samples. $0.2 \mathrm{ml}$ of the suspension was aseptically transferred to microbiological plates of nutrient agar, mannitol salt agar and MacConkey agar and was spread over the media by the use of a sterile bent L-shaped glass rod. This technique was carried out for each tube by spread plate technique and incubated aerobically overnight in an incubator at $37^{\circ} \mathrm{C}$ for $24-48$ hrs. After the incubation period, plates were subjected to examination for microbial growth and the colonies were counted. For the purpose of further analysis pure cultures were obtained through sub-culturing distinct and well characterised colonies. Control samples subjected to the same processes.

\subsection{Identification of isolates from Collected Samples}

In order to be certain about the isolates, pure isolated microbial colonies were identified by the use of their morphological characteristics, Gram staining reaction as well and other biochemical tests which include; coagulase, catalase, indole methyl red voges proskauer citrate (IMVIC), motility, oxidase, urease, triple sugar iron agar (carbohydrate fermentation and the possible gas production) as described by Bergey's manual of determinative bacteriology [11]. In addition to various tests carried out and approved culture media the scientific and practical experiences have had an effective role in the identification of the isolates.

\section{RESULTS}

Evaluation of total of 300 Iraqi paper currency notes were performed, and the average microbial contamination was estimated as $94 \%, 68 \%$, and $60 \%$, respectively on the denominations of 250, 1000, and 5000 Iraqi Dinars (100 samples for each type of the currency notes) illustrated in Fig.1. 


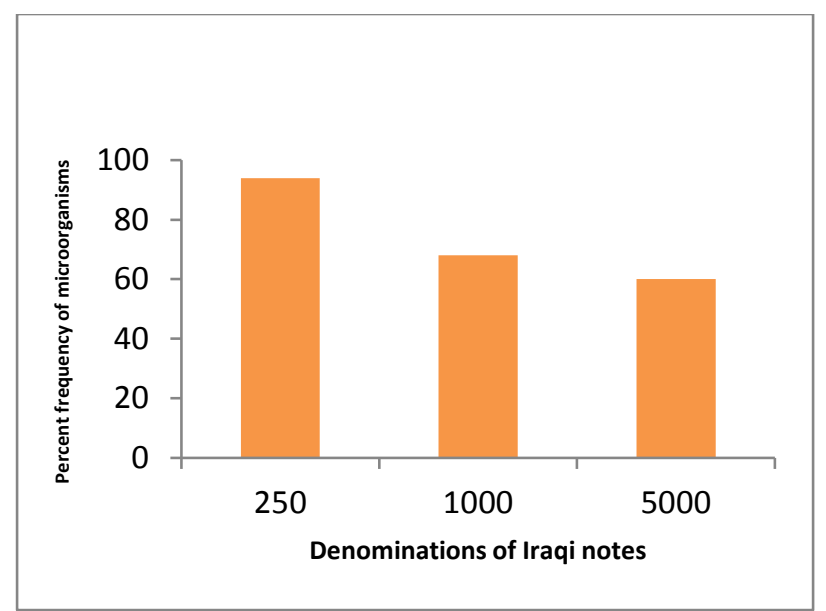

Figure 1: The overall percent frequency of microbes isolated from Iraqi notes

Bacillus sp. was the most prevalent on both of 250 and 5000 currency notes which was $55.31 \%$ and $36.66 \%$, respectively, while scored $32.35 \%$ on 1000 Iraqi Dinars (IQD). However, coagulase negative Staphylococcus has shown the frequency distribution $38.23 \%$ for 1000 Dinar paper currency, whereas $20 \%$ and $14.89 \%$ which is comparable for both denominations 5000 and 250 IQD. The frequency occurrence of Escherichia coli was 20\%, $8.82 \%$, and $8.51 \%$ on 5000,1000 , and 250 paper currency notes under this survey. Results also revealed the frequency (\%) distribution of Pseudomonas sp. as $20 \%, 11.76 \%$, and $2.12 \%$, respectively on 5000,1000 , and 250 sequentially. Klebsiella sp. and Salmonella sp. were similarly found only on 250 currency notes as a ratio of 2.12\%. On 250 IQD, each of Enterobacter sp. and Staphylococcus aureus were distributed in a ratio of $10.63 \%$ and $4.25 \%$, respectively. Moreover, $2.94 \%$ and $5.88 \%$ were recorded as the frequent distribution of Corynebacterium sp. and Serratia sp. on paper denomination 1000 Dinar alone. Proteus sp. occurred on 5000 Dinars with a prevalence ratio of 3.33\%.

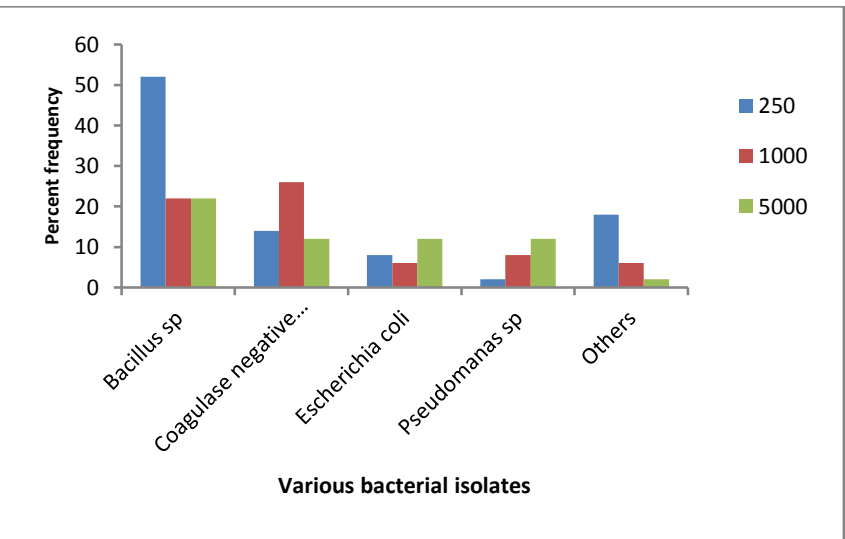

Figure 2: Bacterial isolates with highest incidence in comparison to the lowest other microbes from different denominations

The outcomes of frequency occurrence of different microbial species are visible in Table.1 and Fig.2 which indicate the isolations of Bacillus sp. 52, 22 and 22 and percentage frequency were found to be $52 \%, 22 \%$ and $22 \%$ respectively. Coagulase-negative Staphylococcus count was 14, 26 and 12 with a corresponding frequency of $14 \%, 26 \%$ and $12 \%$. E. coli organisms included were
08,06 and 12 with a frequency of $08 \%, 06 \%$ and $12 \%$ respectively. Pseudomonas sp. organism calculated was 02,08 and 12 with a frequency of $02 \%, 08 \%$ and $12 \%$. Others included microorganisms with minorities shown to be 18,06 and 02 with a corresponding frequency of $18 \%, 06 \%$ and $02 \%$ for 250,1000 and 5000 denominations sequentially.

Table 1: Distributions of bacterial isolates over Iraqi Dinars

Iraqi Dinars Denominations

\begin{tabular}{lcccccc}
$\begin{array}{l}\text { Microorganisms } \\
\text { (bacterial isolates) }\end{array}$ & \multicolumn{2}{c}{$\mathbf{2 5 0}$} & \multicolumn{2}{c}{$\mathbf{1 0 0 0}$} & \multicolumn{2}{c}{5000} \\
\cline { 2 - 7 } & $\begin{array}{c}\text { frequency of } \\
\text { the isolates }\end{array}$ & \multicolumn{2}{c}{$\begin{array}{c}\text { frequency of } \\
\text { the isolates }\end{array}$} & \multicolumn{2}{c}{$\begin{array}{c}\text { frequency of } \\
\text { the isolates }\end{array}$} \\
\hline Bacillus sp. & 52 & $52 \%$ & 22 & $22 \%$ & 22 & $22 \%$ \\
\hline $\begin{array}{l}\text { Coagulase negative } \\
\text { Staphylococcus }\end{array}$ & 14 & $14 \%$ & 26 & $26 \%$ & 12 & $12 \%$ \\
\hline Enterobacter sp. & 10 & $10 \%$ & 0 & 0 & 0 & 0 \\
\hline Escherichia coli & 8 & $8 \%$ & 6 & $6 \%$ & 12 & $12 \%$ \\
\hline Staphylococcus aureus & 4 & $4 \%$ & 0 & 0 & 0 & 0 \\
\hline Klebsiella sp. & 2 & $2 \%$ & 0 & 0 & 0 & 0 \\
\hline Salmonella sp. & 2 & $2 \%$ & 0 & 0 & 0 & 0 \\
\hline Pseudomonas sp. & 2 & $2 \%$ & 8 & $8 \%$ & 12 & $12 \%$ \\
\hline Corynebacterium sp. & 0 & 0 & 2 & $2 \%$ & 0 & 0 \\
\hline Serratia sp. & 0 & 0 & 4 & $4 \%$ & 0 & 0 \\
\hline Proteus sp. & 0 & 0 & 0 & 0 & 2 & $2 \%$ \\
\hline Total & 94 & $94 \%$ & 68 & $68 \%$ & 60 & $60 \%$ \\
\hline
\end{tabular}

However, Fig.3 gives detailed information about isolated microbial species with lowest frequency of occurrence which given the name of others. In which, it can be observed that each of Enterobacter, S. aureus, Klebsiella sp. and Salmonella sp. were only isolated from 250 denomination with frequency of $10 \%, 04 \%$ and $02 \%$ for each of the last two microorganisms. Both of Serratia sp. and Corynebacterium sp. were recorded on paper currency of 1000 IQD only and with frequency of $04 \%$ and $02 \%$, respectively. Proteus sp. with a frequency of $02 \%$ was the sole bacterial isolate from denomination of 5000 Dinars.

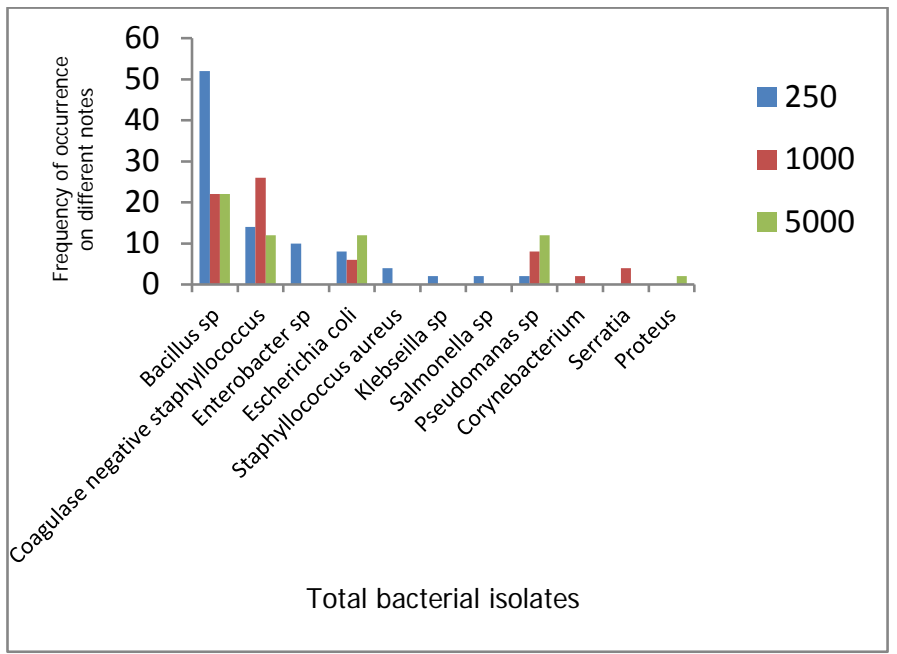

Figure 3: The overall frequency of the microbes isolated from Iraqi paper denominations 


\section{DISCUSSION}

Data collected for this research study approved that Iraqi paper currency (Dinars) is somewhat a hidden and neglected source of infections in Kalar city. Numerous bacterial species were isolated from the lower currencies (250 and 1000 IQD) in comparison to the higher ones (5000 IQD). This might be due to the fact that lower denominations seems like they have been exchanged and handled more frequently in nonessential and daily cash deals [12]. However, control (unused) samples did not support the growth of any group of microorganisms. Similar results were obtained by [12], who also stated that it could be due to impregnation of currency with disinfectant to retard the growth of microorganisms. The rate of contamination of paper currencies selected for this study is in quite close association with other studies performed locally $[13,14,15]$ or from other parts of the world $[16,17,18]$, and that the microbial contaminants are usually those that are the causative agents of a widescale of infectious diseases [19]. Thus, our data demonstrates that the level of contamination within Iraqi denominations in Kalar city is in a risky situation for the people to high extent. In addition to that, it is well known that paper currency notes consists of $75 \%$ cotton and $25 \%$ linen, which makes them vulnerable to the growth, multiplication and as a home for microorganisms [20]. Iraqi denominations are made from the worst types of paper. In fact this might play a significant role in making them more liable for growth and subsequent spread of microorganisms including the pathogenic species as well. Extensive growth of bacterial species could be as a consequence of currency notes with larger surface area on both sides [20]. Moisture makes this notes dirty from this onset, therefore, it supports and provides favorable states to acquire microbes from human body as a result of frequent handling in addition to dust from the surrounding environment [21]. As long as currency notes are exposed to contamination through various sources that include all sorts of contaminants, like contaminated hands or containers, they are made to play as the prospective carrier for the transmission and dissemination of microbes responsible for microbial diseases [22].

Bacterial species isolated from Iraqi notes in descending order were Bacillus sp., Coagulase negative Staplylococci, Escherichia coli, Pseudomonas sp., Enterobacter sp., Staphylococcus aureus, Serratia sp., Klebsiella sp., Salmonella sp., Corynebacterium sp. and Proteus sp. Iraqi notes could have been contaminated by these microorganisms through food, soil, clothing or hands of individuals. Majority of these microorganisms are considered potential pathogens acting as causative agents of infectious diseases [12]. This order is quite similar to those observed by [8, 22, 12], but with a lesser association with that of [1]. This discrepancy could be due to differences in the ratio of local flora or the environmental factors that somehow could have critical impact on the overall bacterial species.

The most prevalent bacterial species on paper currencies in this investigation was Bacillus sp. which is a tremendous kind of tough spore forming species that is normally present in the dust and in case if it is found in the surrounding environment; it is possibly transferred on to the Iraqi notes as a consequence of its placement on unhygienic places or trading with soiled hand. It is obvious that in most of the developing countries this case most commonly could be seen among those who are dealing with fresh and moist animals dairy products in addition to meats. Food poisoning with diarrhea and vomiting were the most clinical cases investigated in people which was caused by Bacillus sp. [23]. Although coagulase-negative Staphylococci (CNS) are implicated in various medical conditions such as endocarditis, urinary tract infections, and responsible for around 30\% of overall nosocomial blood stream infections, they are widely known as normal microbiota of human skin and mucous membrane [24]. However, S. aureus is always associated with various superficial and deeper infections which penetrate human's body via any sorts of cuts, breaks and scrapes in the skin [25], in addition to foodborne diseases [26]. Simply, presence of Staphylococcus species on studied Iraqi denominations probably due to rubbing between hands or accidently contacting either nose or mouth, which are various sorts of unusual habits of some individuals when they engaged in cash transactions. Undoubtedly, these are the strongest sources for the spread of pathogenic bacteria via currency notes which we should be concerned about.

Furthermore, presence of Escherichia coli, the cause of urinary tract infections [27], and various other infections like diarrhea, an enteric pathogen on Iraqi Dinars, indicates habitat with poor hygienic conditions as well as poor individual hygienic implementation noticed by the majority of the professional groups [1]. Pseudomonas species observed to some extent on IQD. This bacterial group, especially the species aeruginosa is considered as one of opportunistic bacilli that is able to contaminate diseases on the skin or open wounds, burns or may also cause typical cutaneous lesions [28]. Corynebacterium species with a lesser frequency has been linked to different medical cases, for example, upper respiratory and skin infections, enteritis, meningitis and other conditions [29]. Bacterial species isolated with minorities on Iraqi denominations were Klebsiella and Proteus species, which are stood behind various infectious diseases including nosocomial infections, urinary tract infections and septicemia, in case if they have a chance of contact with sensitive people [30]. It is expected that either the water which was utilized to moisten the fingers of traders while counting currency denominations was contaminated with the last two bacterial species or cross contamination from sewage [12].

\section{CONCLUSION}

It can be concluded that the percentage of bacterial contamination on the three selected Iraqi currencies is really interesting and risky, especially those on the category of 250 IQD. Additionally, the problem is that pathogenic bacteria represent the majority of those bacterial isolates, particularly Bacillus sp. which are most often able to produce resistant spores which enables them to resist difficult or unfavorable conditions for their growth and reproduction. These conditions involved environmental factors, for example, extreme temperature, depletion of nutrients, dryness, and changes 
in the $\mathrm{pH}$ of the surrounding environment. Therefore, those bacterial species as well as their risk can remain viable on the paper currencies for longer period of time. $E$. coli is also among those problematic bacteria that can cause various diseases including diarrhea, indicates that paper denominations were contaminated with offal's. Overall, it reflects poor sanitation and poor hygienic awareness among individuals of the population. Therefore, and as a precautionary measure citizens should be warned of the risk of infections with these pathogenic bacterial species, which exploit monetary currency as a hidden sources for the transfer to new hosts and developing infectious diseases.

\section{REFERENCE}

[1] G. Sucilathangam, A. M. Reventh, G. Velvizhi, C. Revathy, "Assessment of Microbial Contamination of Paper Currency Notes in Circulation,” nt.J.Curr.Microbiol.App.Sci, 5(2), pp. 735-741, 2016.

[2] R. M. Podhajny, "How dirty is your money? Paper, Film and Foil Converter,” 78(1), pp, 21, 2004. Saudia.

[3] H. W. Charnok, “A preliminary bacterial study of Egyptian paper money,” International Journal of Environmental Health Research, vol. 15, pp. 235-246, 2005.

[4] H. Haque, A. Itoda, "Bacterial load of Nigeria currency Naira and Kobo," B.Sc Thesis, Department of Microbiology, University of Jos, Nigeria, 2003.

[5] B. A. Freeman, "Burrows Textbook of Microbiology," 22nd edition, Philadelphia: WB Saunders Co, 1985.

[6] E. Jawetz, J. L. Melnick, E. A. Adelberg, "Review of Microbiology,” California: Lange Pub; 1987.

[7] R. A. Weinstein, B. Hota, "Contamination, disinfection, and cross colonization: are hospital surfaces reservoirs for nosocomial infection?” Clinical Infectious Diseases, 39(8), pp. 1182-1189. 2004.

[8] S. N. Jafer, H. H. Mohammed, Z. E. Saleh, "Bacterial contaminations of Iraqi Currencies collected from Duhok City, Iraq,” Int J Res Med Sci, 3(7), pp. 1712-1716, 2015.

[9] H. Gedik, M. Yahyaoğlu, G. Yörük, M. Fincanc1, "ExtendedSpectrum Beta-Lactamase production Rates of Klebsiella spp. and Escherichia coli strains Isolated from infections and faecal samples of healthy people,” Infectious Diseases in Clinical Practice, 18, pp. 104-106, 2010.

[10] N. Oo. Khin, W. P. Phyu, M. H. Aung, T. Aye, "Contamination of currency notes with enteric bacterial pathogens,” Journal of Diarrhoeal Diseases Research, 7(3/4), pp. 92-94, 1989.

[11] D. H. Bergey, J. G. Holt, “Bergey's Manual of Determinative Bacteriology,” Philadelphia, Lippincott Williams \& Wilkins, 2000.

[12] O. Ndubuisi, I. Iheukwumere, E. Uzochukwu, E. A. Otutu, A. K. Victor, "Evaluation of Micro-Pathogens Associated with Nigerian Currency (Naira Notes),” World Scientific Research, Vol. 3, No. 1, pp. 16-22, 2016. (journal style)

[13] H. S. Abid, "Bacterial Contamination of Iraqi Paper Currency Notes in Circulation \& Resistance of Pathogenic Bacteria to Antibiotics,” Iraqi Journal of sciences, 53, pp. 81-7, 2012.

[14] S. M. Abdulla, "Isolation and Identification of causative agents from some Iraqi Banknote currency,” Ibn Al-Haitham Journal for Pure \& Appl Sci, 26(1), pp. 75-81, 2013.

[15] I. J. AL-Abbasi, "Investigation of bacterial contamination in Iraqi paper currency,” Journal of Kerbala University, Scientific, 8(3), pp. 74-82, 2010.

[16] B. O. Emikpe, O. G. Oyero, "Preliminary Investigation on the Microbial Contamination of Nigerian Currency," Int J Trop Med, 2, pp. 29-32, 2007.

[17] P. Felgo, M. Nkansah, “ Bacterial Load on Ghanaian Currency Notes,” Afr J Microbiology Research, 4(22), pp. 2375-80, 2010.

[18] P. J. Guerin, C. Brasher, E. Baron, D. Mic, F. Grimont, M. Ryan, P. Aavitsland, D. Legros, "Shigella dysenteriae serotype 1in West Africa: Intervention Strategy for an Outbreak in Sierra Leone,” Lancet, 362, pp. 705-6, 2003.

[19] O. Basavaraja, T. W. Pope, P. T. Ende, W. K. Woelk, M. A. Koroil, and T. M. Korosol, "Bacterial contamination of paper currency,” Southern Med. J., vol. 45, pp. 1406-1410, 2005.
[20] E. Angelakis, E. I. Azhar, F. Bibi, M. Yasir, A. K. Al-Ghamdi, et al, "Paper money and coins as potential vectors of transmissible disease," Future Microbiology., 9(2), pp. 249261, 2014.

[21] O. J. Haqu, W. O. Dawin, and E. J. Cone, "Cocaine contamination of United States, paper currency," Journal of Analytical Toxicology, vol. 20, pp. 213-216, 2003.

[22] M. M. Ahmed, F. Fatima, M. J. Ansari, R. Al-Shdefat, M. K. Anwer, S. Jamil, M. Ahmed, Y. Saeed, M. Noor, P. Katakam, Aleemuddin. M, A. Farheen, "Bacterial contamination of Saudi Arabian paper currency: A report from Al-Kharj," Advancements in Life Sciences, Volume 4, Issue 2, February 2017.

[23] F. Silma, "Manual of food quality control food and nutrition paper, United Nations, Rome, Italy," Microbiological Analysis, vol. 14, pp. 1-20, 2001.

[24] A.Piette, G.Verschraegen, "Role of coagulase-negative staphylococci in human disease,” Volume 134, Issues 1-2, pp. 45-54, 2009.

[25] M. J. J. Pelczar, E. C. S. Chan, N. R. Ang, and M. F. Pelezar, Microbiology, 5th ed. Delhi: Tata McGraw Hill Publishing Company Limited, 1993.

[26] P. R. W. Mass, S. W. Tenths, and L. Simorisen, "Trends in infectious diseases mortality in the United States,” J. Am. Med. Ass., vol. 275, pp. 189-193, 2015.

[27] D. S. Lee, S-Ju. Lee, H-S. Choe, "Community-Acquired Urinary Tract Infection by Escherichia coli in the Era of Antibiotic Resistance,” Hindawi, BioMed Research International, 14 pages, 2018.

[28] E. Rallisa, V. Paparizosb, A. Flemetakisb, A. Katsambasb, "Pseudomonas fingernail infection successfully treated with topical nadifloxacin in HIV-positive patients: report of two cases,” AIDS, Vol 24 No 7, pp. 1077-1090, 2010.

[29] S. T. Cowan, "Cowan and steal's manual for the identification of medical bacterial,” 2nd ed, United Kindom, Cambridge University Press, 2001.

[30] F. J. Galvani, R. E. Silverton, "Introduction to medical laboratory technology," 6th ed, UK: Buthterworth, and Co Publishers Limited, 2004. 